\title{
Desertification Combating and Ecological Restoration of Selected Acacia Species from Sub-Sahara, Savanna Regions
}

\author{
Mulik Abbaker Ibrahim Yousif ${ }^{1,2}$, Yan Rong Wang ${ }^{1, *}$ \\ ${ }^{1}$ State Key Laboratory of Grassland Agroecosystems, College of Pastoral, Agricultural Sciences, and Technology, Lanzhou University, \\ Lanzhou, P. R. China \\ ${ }^{2}$ Department of Forestry Sciences, Zalingei University, Zalingei, Sudan
}

\author{
Email address: \\ yrwang@1zu.edu.cn (Yan Rong Wang) \\ ${ }^{*}$ Corresponding author
}

\section{To cite this article:}

Mulik Abbaker Ibrahim Yousif, Yan Rong Wang. Desertification Combating and Ecological Restoration of Selected Acacia Species from Sub-Sahara, Savanna Regions. American Journal of Agriculture and Forestry. Vol. 9, No. 4, 2021, pp. 164-171.

doi: 10.11648/j.ajaf.20210904.11

Received: June 2, 2021; Accepted: June 17, 2021; Published: June 23, 2021

\begin{abstract}
The Acacia species are widely distributed in the Sub-Sahara, Savanna regions and are of significant importance in terms of ecological remediation, afforestation programming, and economic value. Seed dormancy is common in Acacia species, and it creates difficulties in seed testing and planting. The initial aim of the current study was to assess the influence of a different temperature and different levels of water potential for germination based on the hydrothermal time models that had been successfully prophesying germination demand in several threat categories. Seeds of four Acacia species were treated at different temperature $\left(15^{\circ} \mathrm{C}, 20^{\circ} \mathrm{C}, 25^{\circ} \mathrm{C}, 30^{\circ} \mathrm{C}\right.$ and $\left.35^{\circ} \mathrm{C}\right)$ and different levels of osmotic stress $(0,-.4,-0.8$, and $-1.2 \mathrm{MPa})$. The results revealed that the degree of dormancy variation among the species, they were $81 \%$ for $A$. nilotica, $74 \%$ for $A$. seyal, $15 \%$ for $A$. mellifera, and $5 \%$ for $A$. senegal. Whereas, the optimal temperatures responded is $25^{\circ} \mathrm{C}$ for A. seyal, and $A$. senegal, $A$. nilotica, and $20^{\circ} \mathrm{C}$ for $A$. mellifera. Therefore, there are negative correlations appeared within germination percentages and water potential, A. seyal, and $A$. senegal was displayed a drought-tolerant significantly lower levels of water stress. In contrast, $A$. nilotica and $A$. mellifera indicated less drought-tolerant of promoting water stress.
\end{abstract}

Keywords: Acacia, Temperature, Water Stress, Hydrothermal Time, Germination, Drought, Restoration

\section{Introduction}

Acacia species are rising normally in Savanna areas, there are most serious sources noted to be useful for livelihoods, gum, food, fuel, firewood, timber, forage, fiber, tannins, domestic utensils, handicrafts, nitrogen-fixing, soil stabilization, medicine, ornamentals, shade, shelter, and Agroforestry system. Besides, have a significant trait in degraded land in arid, semi-arid and desert districts. Acacia seyal, A. nilotica, A. mellifera, and A. senegal are the most promising fodder trees and their flowers, bark, fruits, gum, roots, and stems used for medicinal purposes $[1,2]$. Whereas, these species adapt to very erratic climate conditions in dunes arid, semi-arid, desert, and saline land, further protective environmental conditions [3]. Along with, thus, it can live in high temperatures and drought sand [4-7]. So, desertification combating and drought is one of the most severe environmental stresses affecting trees and crop growth and development and ultimately reducing yield potential [8]. Besides, drought acceptance is a multifaceted trait that involves several morphological adaptive and metabolic ways. Thus, deciphering the genetic basis of drought tolerance mechanisms in plants remains a challenging task [9]. Indeed, the temperature is an essential trigger for seed germination, of Acacia species require light within $20-30$ and $25,35^{\circ} \mathrm{C}$ [10-13].

Further, many studies evaluated the effect of water potential and temperature in seed germination ability modeled by hydrothermal time models [14-16]. This model has been multiple purposes to process seed germination 
progress also provide measuring of yield coefficients and the physiological time those frequently used to show potential rank temperature, screen germplasms and water probable responses of species [14, 17-19]. The borders defined as three models to get the measure of germination response of water stress and temperature. Furthermore, the benefit of knowing about the ecological relationships within plant species. Seed germination response to water potential and temperature of several species, ecosystems have been resolved independently [20-24]. However, soaking osmotic solutions such as polyethylene glycol (PEG), glycol, in seeds able broke seed dormancy and promoting seedling growth [25]. Appropriate periods of priming depending on osmotic chosen, of water stress, osmotic solution, temperature during priming, and plant species [26]. The priming method was presented for breaking seed dormancy and enhancing seedling growth also priming allows the metabolic procedure to be necessary for germination before actuality germination to get the start [27]. The positive effects of priming have been indicated for various species, for instance, chickpea [28, 29]. Shorter germination time, emergence overall seedbed environmental and broad temperature range of germination, leading to homogeneity, the best crop establishment and improved harvest yield and quality, particularly under stress and the abnormal situation in the field are the typical responses to seed priming [1, 30]. Moreover, the influence of temperature and water potential on seed germination could be modeled by hydrothermal time models [14-16, 31]. There are little data about the effect of osmotic stress and temperature on Acacia seed germination [5, 32-34]. This makes vital candidate species for food and forage trees in drylands [35]. Acacia species have evolved many strategies to adapt to dune sand and drought surface environment, including rapid growth after germination, long hypocotyl, and pronounced drought and heat tolerance [35, 7]. Therefore, most Acacia species have durable seed coats impervious to water. One of the characteristics of the seeds of some desert species is a thick testa that does not allow water to enter [36]. Although, this species represents a new tree alternative for the future providing as food and forage production [2, 37, 38].

The present work evaluates the influence of different levels of salt stress and also temperature for germination according to the hydrothermal time model's response of selected Acacia seeds, and identify the more tolerant in under drought stress.

\section{Materials and Methods}

\subsection{Seed Collection}

Seeds of Acacia seyal, A. nilotica, A. senegal, and $A$. mellifera were collected from Darfur, Western Sudan. The seed collection from December 2015 to February 2016, the mean yearly temperature is $20-30^{\circ} \mathrm{C}$, with an average annual rainfall of 200-1200 $\mathrm{mm}$. The seeds were selected by sorting out the healthy, uninfected seeds of almost uniform size. These seeds were stored in plastic boxes at $5^{\circ} \mathrm{C}$ and were used for evaluating different treatments.

\subsection{Impact of Water Potential}

The influence of water potential on germination was tested by incubating seeds at $20^{\circ} \mathrm{C}$ lights for 21 days. Samples of four replicates of 50 seeds were used for each treatment. Seeds were examined by diverse stages of (PEG 6000) solution that preciously created three levels of osmotic potential $(0,-0.4,-0.8$, and $-1.2 \mathrm{MPa})$ [39].

\subsection{Influence of Temperature}

Temperature responses were examined in scarifying seeds incubated at several temperatures $\left(15^{\circ} \mathrm{C}, 20^{\circ} \mathrm{C}, 25^{\circ} \mathrm{C}, 30^{\circ} \mathrm{C}\right.$ and $\left.35^{\circ} \mathrm{C}\right)$.

\subsection{Influence of Hydrothermal Time}

Thermal time model of the cumulative germination values [probit (g)], suboptimal temperature range and supra-optimal temperatures were regressed and pooled against a function of time $\left(\mathrm{t}_{\mathrm{g}}\right)$ also temperature $(T)$ Eq. 1 [40].

Probit $(g)=\left[\log \left(T-T_{b}\right) t_{g}-\log \left({ }^{\theta}{ }_{\mathrm{T}(50)}\right] /{ }^{\sigma}{ }_{\theta \mathrm{T}}\right.$ probit $(g)$ is the probit transformation of cumulative germination percentage $g$, which linearizes the sigmoidal time subjected in a long-timescale [41]. $T_{\mathrm{b}}$ base temperature under which seed did not germinate, $T$ germination temperature, ${ }^{\theta}{ }_{\mathrm{T}}(50)$ median thermal time to germinate, $t_{g}$ actual time to germination of fraction $g$ and ${ }_{\theta \mathrm{T}}$ standard deviation of $\log { }^{\theta} \mathrm{T}$ demand between individual seeds or the population of the slope of the probit of a regression line. Those cumulative germination values [probit $(g)$ ], whole times as well as, supra-optimal temperatures were regressed and pooled against a function of time $\left(t_{g}\right)$.

However, temperature $(T)$ as in Eq. 2 [42-44]. probit $(g)=$ $\left.\left[\mathrm{T}+{ }^{\theta}{ }_{\mathrm{T}} / t_{g}\right)-\mathrm{T}_{\mathrm{c}(50)}\right] /{ }^{\sigma} \mathrm{Tc}$.

When ${ }^{\theta} \mathrm{T}$ is the thermal time constant of whole individual seeds, ${ }^{\sigma} \mathrm{T}_{\mathrm{c}}$ the standard deviation within individual seeds in the population of the slope of the probit regression line and $T_{\mathrm{c}(50)}$ the median temperature of germination. The value of $T_{\mathrm{c}}(50)$ able to get from the regression of the time when $g=50 \%$ and probit $(\mathrm{g})=0 .{ }^{\theta} T$ was evaluated by the iterative method. The ${ }^{\theta} \mathrm{T}$ produced the least residual was considered to be the best estimate of ${ }^{\theta} \mathrm{T}[31]$. For hydro time model $[45,46]$. possible to define as:

$$
{ }^{\theta} \mathrm{H}=\left[\Psi-\Psi_{\mathrm{b}}(g)\right] t_{g}
$$

When ${ }^{\theta} \mathrm{H}$ is the hydro time constant of fixed seed population, $\Psi_{\mathrm{b}}(\mathrm{g})$ the threshold water potential of a specific germination fraction $g, \Psi$ the reality water potential of germination testing, and $t_{g}$ the real-time to germination of fraction $g$. The normal distribution of $\Psi_{\mathrm{b}}(\mathrm{g})$ values between seeds on the population are propertied by the median $\left[\Psi_{\mathrm{b}(50)}\right]$ and standard deviation $\left({ }^{\sigma} \Psi_{\mathrm{b}}\right)$, the formula able to derived using continuous probit analyses to describe ahead $[46,40]$. probit $(g)=\left[\Psi-\left({ }_{H}^{\theta} / t_{g}\right)-\right.$ $\left.\Psi_{\mathrm{b}(50)}\right] /{ }^{\sigma}{ }_{\Psi \mathrm{b}}$

Kindness-of-fit among the observed and predicted data was estimated using the coefficient of the determination $\left(R^{2}\right)$. 


\subsection{Seed Germination Test}

The seed germination was exposed before and after the final experiment incubated at $20^{\circ} \mathrm{C}$. Four replicates of 50 seeds were used for each treatment in the experiment and placed on top of 2 layers of filter paper in $90 \mathrm{~mm}$ Petri dishes. A seed was considered to have germinated when the radical extension was at least $0.5 \mathrm{~cm}$. Seeds were evaluated according to the international rules for seed testing association [47]. The experiments were laid out in a completely randomized design.

\subsection{Statistical Analysis}

Differences of water potential and temperature is affected in germination rate $\left(1 / T_{50}\right)$ and germination percentage of seed species were analyzed using SPSS 20.0 software by using one-way ANOVA $(P<0.05)$. Duncan's multiple range test was followed to compare means of the germination rate $\left(1 / T_{50}\right)$ and germination percentage within treatments on each species when significant differences.

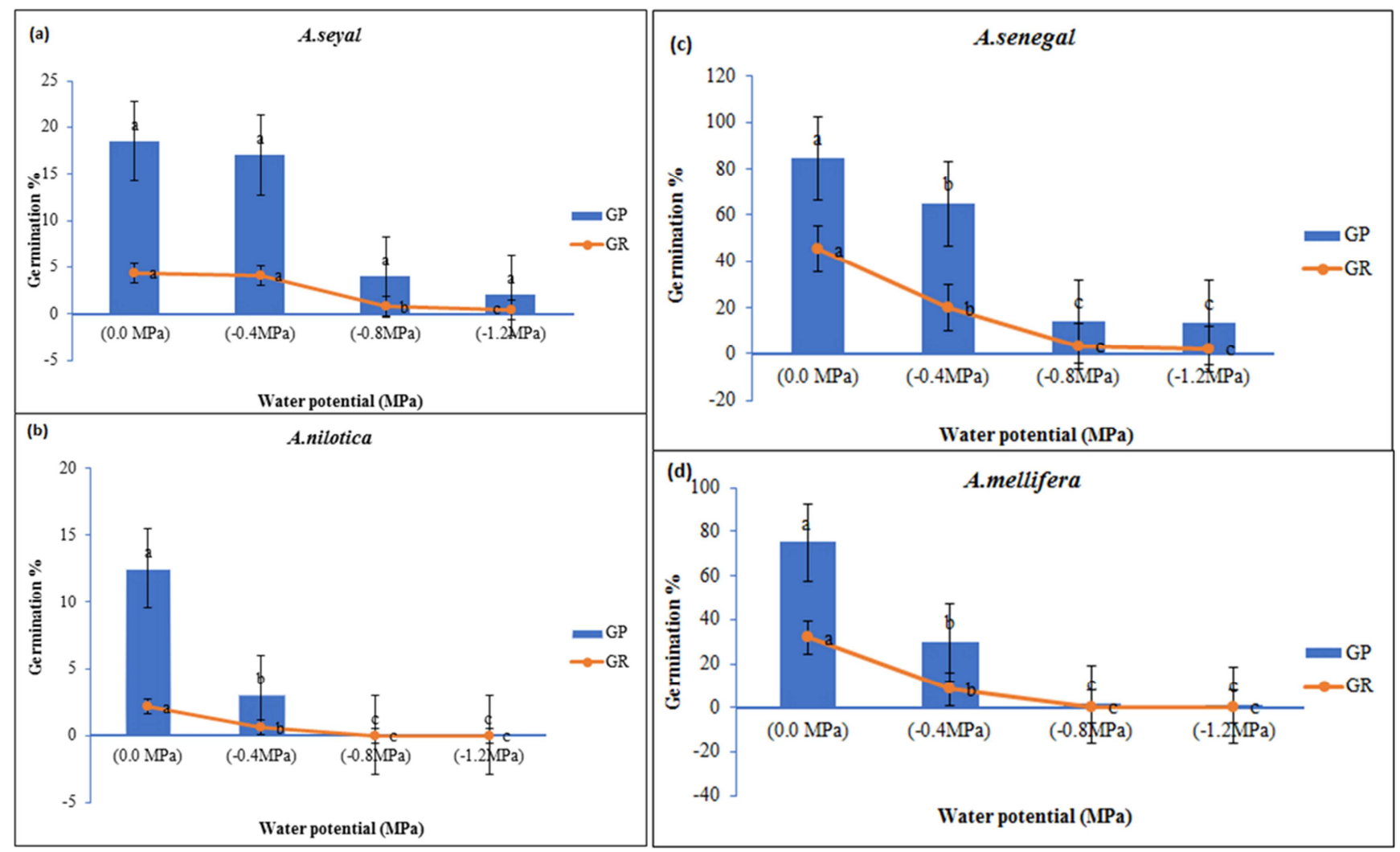

Figure 1. $a, b, c$, d. Seed germination percentage and rate of Acacia species at water potential.

\section{Results}

\subsection{Effect of Water Potential Performance}

A significant influence of water stress on germination percentage and germination rate $(P<0.05)$. Germination percentage of $A$. nilotica and A. mellifera was failed to germinate at (- 0.8 and $-1.2 \mathrm{MPa})$. Consequently, significantly diminished by $(-0.4 \mathrm{MPa})$. Germination percentages of $A$. seyal and $A$. senegal were significantly declined by $(-1.2 \mathrm{MPa})$. Germination rates generally reduced as water stress decreased, which is always associated failed of seed emergence. The fitted with hydro time models displayed the germination dynamics of whole $A$. species perfect for responding high-water stress $(>-0.4 \mathrm{MPa})$. Though, there is a failure to display germination dynamics in low water stress $(<-1.2 \mathrm{MPa})$ in those species (Figure 1a, b, c, d).

\subsection{Impact of Temperature Performance}

The temperature has a significant influence on percentage and germination rate $(1 / T 50)$ for each species $(P<0.05)$. Germination percentage of $A$. mellifera and $A$. senegal permeable seed dormancy lead to in high germination at $20^{\circ} \mathrm{C}$, $75 \%, 84.5 \%$, and $25^{\circ} \mathrm{C}, 80 \%, 88.5 \%$, respectively. Moreover, significantly decreased by $30^{\circ} \mathrm{C} 15.5 \%, 11 \%$ and $35^{\circ} \mathrm{C}, 13 \%$, $8 \%$. Germination percentages of A. seyal and A. nilotica, impermeable seed coat dormancy, were shown germination at $20^{\circ} \mathrm{C}, 18.5 \%, 12.5 \%$, and $25^{\circ} \mathrm{C}, 20.5 \%, 14.5 \%$, respectively. Further, significantly diminished by $30^{\circ} \mathrm{C}$ and $35^{\circ} \mathrm{C}$. Germination rates generally enhanced as temperature increased and then decreased as temperature increased. Germination rate regularly improving linearly with increased temperature up to a maximum point, after that, diminished to a ceiling temperature (Figure 2a, b, c, d). 

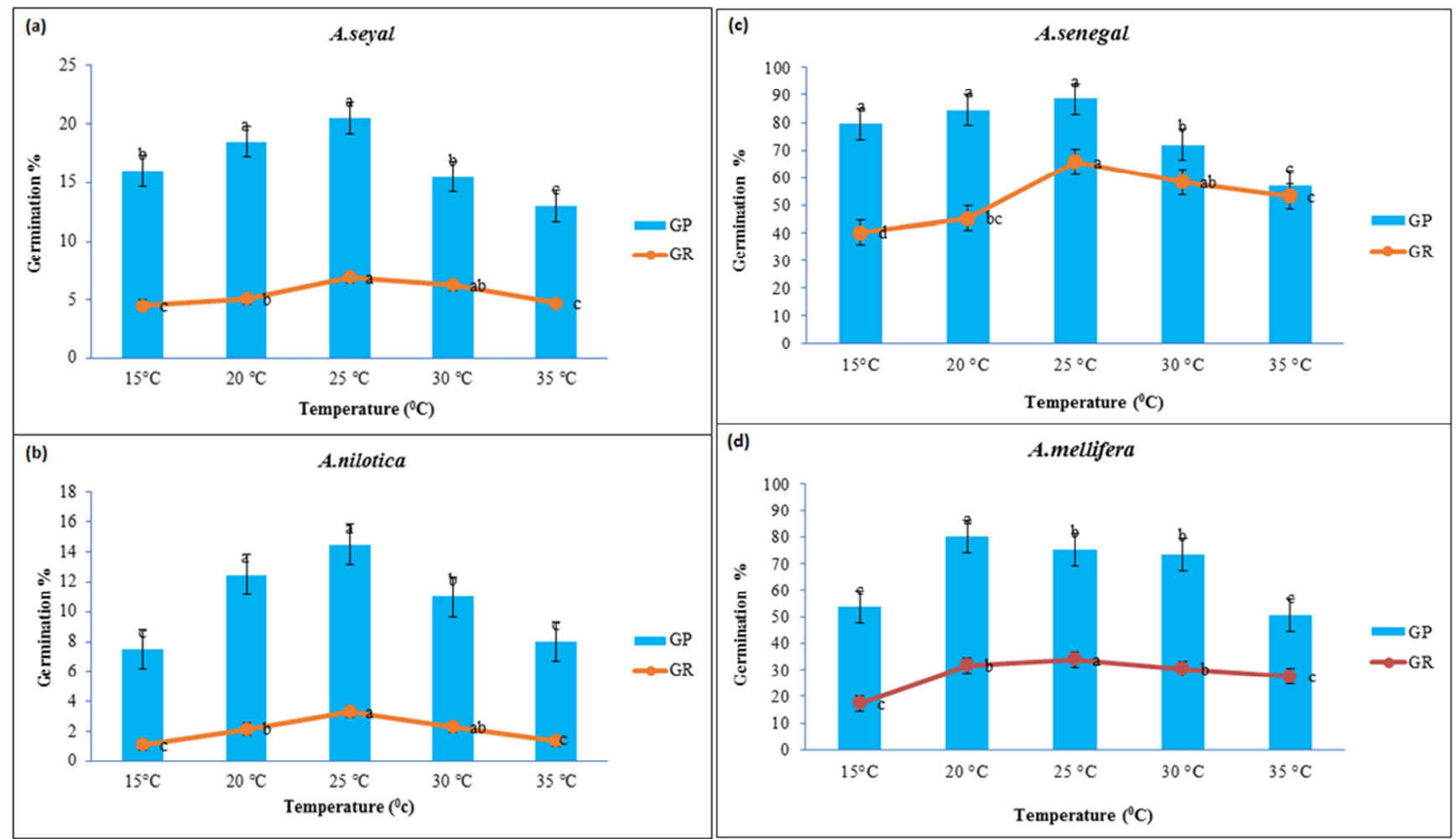

Figure 2. a, b, c, d. Seed germination percentage and rate of Acacia species at different temperature ranges.

\subsection{Influence of Hydrothermal Time Models}

The hydrothermal time models have indicated excellent germination time when exposed Acacia seeds in various water stress and temperatures. The subtleties of seed germination of Acacia species in temperature were outstandingly depicted the thermal time model in supra-optimal and suboptimal temperatures. Nevertheless, there was no difference within those species at ${ }^{\theta} \mathrm{T}(50)$ and $T \mathrm{c}(50)$ in supra-optimal and suboptimal temperatures (Figures 3, 4; Tables 1, 2, 3).

Table 1. Seed germination parameters of Acacia species, based on thermal-time model analysis at suboptimal temperature.

\begin{tabular}{lllll}
\hline Species & ${ }^{\boldsymbol{\theta}}{ }_{\mathbf{T}(5)}\left({ }^{\circ} \mathbf{C}\right)$ & ${ }^{\sigma}{ }_{\boldsymbol{\theta} \mathbf{T}}$ & $\boldsymbol{T}_{\mathbf{b}}\left({ }^{\circ} \mathbf{C}\right)$ & 0 \\
\hline Seyal & 50 & 0.1 & 10 & 0 \\
Nilotica & 50 & 0.1 & 10 & 0 \\
Senegal & 50 & 0.1 & 10 & 0 \\
A. mellifera & 1.22 & 39.3 & 0.58 & 0.46 \\
\hline
\end{tabular}

Notes: $T_{\mathrm{b}}=$ constant base temperature in suboptimal temperature range, $\theta_{\mathrm{T}(50)}=$ thermal time on $50 \%$ of germinate seeds, ${ }_{\theta \mathrm{T}}=$ standard deviation for ${ }^{\theta} \mathrm{T}(50)$.

Table 2. Seed germination parameters of Acacia species based on thermal-time model analysis at supra-optimal temperature.

\begin{tabular}{lllll}
\hline Species & $\boldsymbol{T}_{\mathbf{c}(\mathbf{5 0})}\left({ }^{\circ} \mathbf{C}\right)$ & ${ }^{\sigma} \mathbf{T}_{\mathbf{c}}$ & ${ }^{0} \mathbf{T}\left({ }^{\circ} \mathbf{C d}\right)$ & $\boldsymbol{R}^{\mathbf{2}}$ \\
\hline A. seyal & -331.7 & -411.1 & 1140.6 & 0.679 \\
A. nilotica & -2.40 & -2.63 & 1.84 & 0.581 \\
A. senegal & 82.8 & -57.4 & 184.1 & 0.510 \\
A. mellifera & 2.13 & -2.67 & 1.47 & 0.639 \\
\hline
\end{tabular}

Notes: $T_{\mathrm{c}(50)}=$ ceiling temperature on $50 \%$ of germinate seeds, ${ }^{\sigma} \mathrm{T}_{\mathrm{c}}=$ standard deviation for $T_{\mathrm{c}(50)}$ at supra-optimal temperature ${ }^{\theta} \mathrm{T}=$ constant thermal time.

Table 3. Seed germination parameters of Acacia species, water potential based on hydro-time model analysis.

\begin{tabular}{lllll}
\hline Species & $\left.{ }_{\mathbf{H}} \mathbf{( M P a . d}\right)$ & $\boldsymbol{\Psi}_{\mathbf{b} \mathbf{( 5 0 )}} \mathbf{( M P a )}$ & ${ }^{\boldsymbol{\sigma}}{ }_{\mathbf{\Psi} \mathbf{b}}$ & $\boldsymbol{R}^{\mathbf{2}}$ \\
\hline A. seyal & 6.10 & 0.50 & 0.98 & 0.88 \\
A. nilotica & 7.08 & 0.77 & 0.84 & 0.91 \\
A. senegal & 3.08 & -0.66 & 0.44 & 0.90 \\
A. mellifera & 1.75 & -0.26 & 0.38 & 0.90 \\
\hline
\end{tabular}

Notes: $\Psi_{\mathrm{b}(50)}=$ base water potential on $50 \%$ of germinate seeds, ${ }^{\theta} \mathrm{H}=$ constant hydro time, ${ }^{\sigma}{ }^{\mathrm{w} b}=$ standard deviation of $\Psi_{\mathrm{b}(50)}$. 


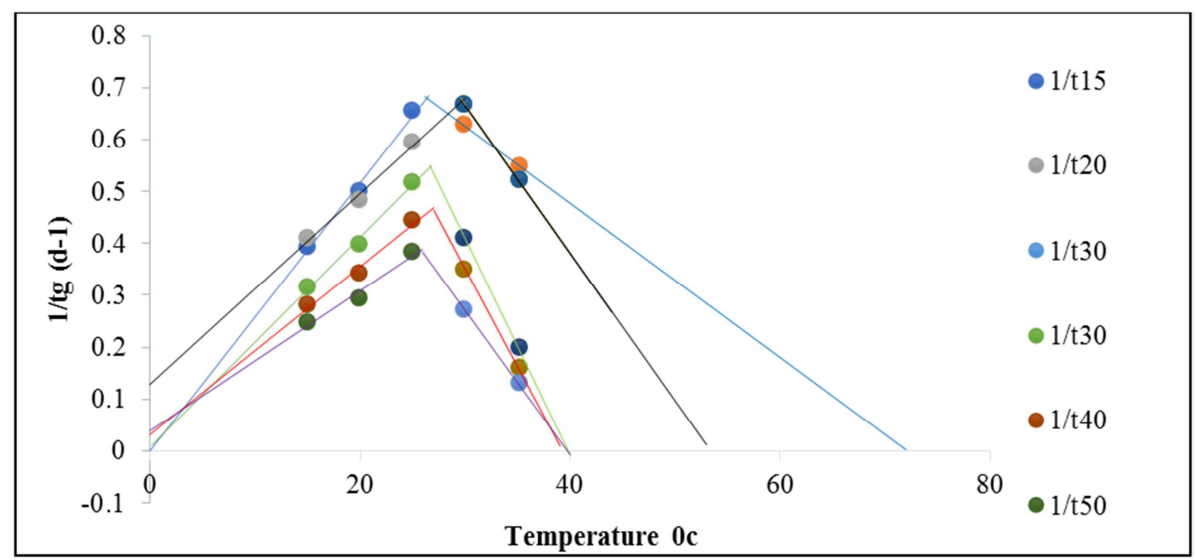

Figure 3. Linear regression for germination rate $\left(1 / t_{\mathrm{g}}\right)$ of each temperature and subpopulation at supra-optimal and suboptimal temperature ranges of $A$. senegal.

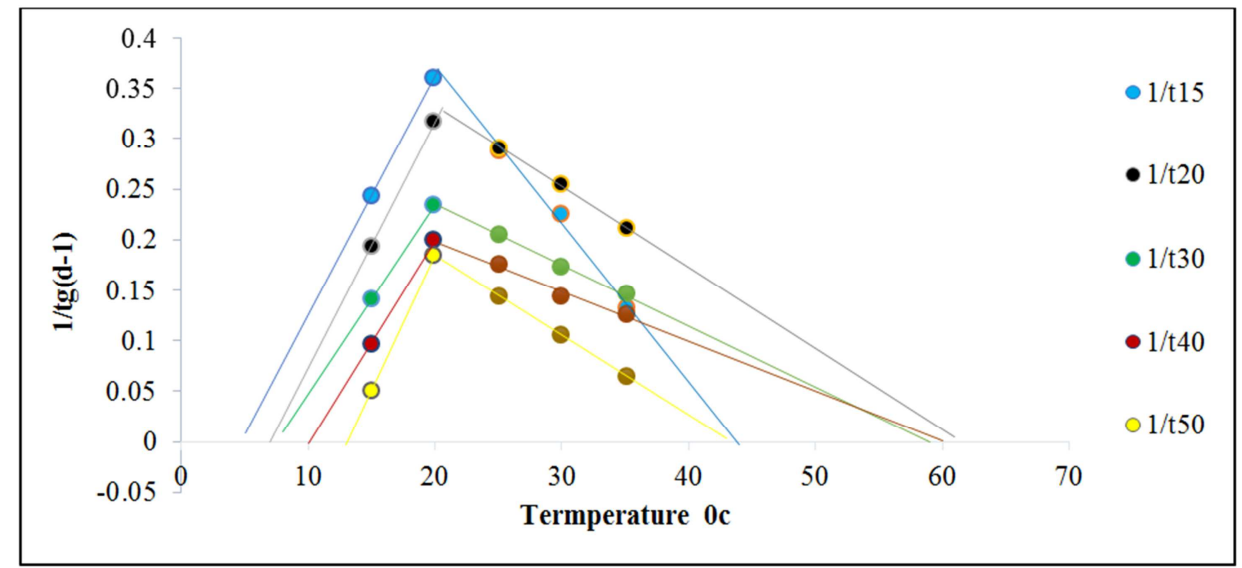

Figure 4. Linear regression for germination rate $\left(1 / t_{g}\right)$ of each temperature and subpopulation at supra-optimal and suboptimal temperature ranges of $A$. mellifera.

\section{Discussion}

This study presented that the water stress for A. nilotica and A. mellifera, exhibited higher sensitivity and less tolerance to encourage water stress than other species. Supplementary A. senegal and A. seyal could germinate at lower water stress $(-1.2 \mathrm{MPa})$. Germination responses to water stress and temperature of Acacia seeds can relate to the plant ecology and naturally seedling survived after germination is in need of soil water availability. The current research justified with previous researches of another species [48-52]. The capability of the seeds to germinate in low soil water, water stress can enhance ecological advantages of the species that permit to display in areas anywhere less resistant drought species should not. Seeds that they germinate below low water availability after a rainfall incident. [53] recommended that considering plant populations and seed characteristics, do not follow a regular pattern. This means that some species, the impact of drought created with (PEG 6000) on germination is not significant, and germination was not influenced by drought stress. [54] description that the negative potentials between (-0. 4 and -0 . $8 \mathrm{MPa}$ ) are the better condition for studying the germination surface of different genotypes of plants under drought stress. The temperature responses of the plants to view the environments in which they are adaptable. Even more, differences within the species have substantial ecological significance $[55,23]$. Species from tropical sections ordinarily require high-level temperature for germination in temperate species [56]. The optimal temperature for germination of four Banksia species has been positively correlated together with the mean annual temperature in the area of seed originates [57, 58].

For the existing study, the seed germination of Acacia species completely more tolerant of low temperatures. The hydrothermal time models have been indicated that the hydro time and thermal time models may describe very well the germination time course of scarified Acacia seeds in various water potentials and temperatures. Furthermore, the recent research justified with previous researches of another species $[58,17,55,24]$. A benefit of these two models to seeds incubated across a range of water potentials and temperatures is that the similarity and variation in germination able to ascribe to define underlying factors, for example, ${ }^{\circ} T, T_{\mathrm{b}}$, and ${ }^{\theta} T_{(50)}[15]$.

Additionally, the summary derived from the parameters of these two models is compatible with the raw data also, more 
comfortable to compare and understand between these species $[15,24]$. The content of these, $\Psi_{\mathrm{b}(50)}$ and $\mathrm{Tb}$ designate a similar trend within species by their response to water potential and temperature. Even more, hydrothermal time, that standard deviation as early as providing very important information that the biological and ecological significance, such as seeds those had high $\Psi_{\mathrm{b}(50)}$ and low ${ }^{\theta} H$ can have a rapid germination rate by nothing water potential, but to be strong support inhibited of germinating in lower water stress species $[17,24]$.

\section{Conclusion}

Differences have been found between four species in their reaction to these treatments. The most resistant to drought conditions are $A$. seyal and $A$. senegal, which may specify the potential for a further selection of drought-tolerant of lines for future climate scenarios. It seems that the potential osmotic levels were most cynical. The hydrothermal time models performed incredibly to demonstrate the germination time course of scarified seeds of these Acacia species in response to water stress and temperature, the models possible to be useful materials in comparative researchers for germination of seeds of the plants that they produce seeds efficacious by physical dormancy.

These outcomes raised the most critical trait of water stress, and temperature response efficiency in the seed of Acacia species will be resulting in the future to promote sustainable agriculture, livelihoods, ecological restoration, afforestation program and degradation lands in arid, semi-arid and desert regions.

Our study is very instructive research, we recommended for follow-up in future work, also, it would be much better to carry additional studies using molecular data, which could be contributing to the open a new field of research to identify genotypic differences and dormancy behavior which are genetically controlled.

\section{Acknowledgements}

The authors are grateful to Dr. Liu Ya Jie and Yu Ling, for providing competent technical assistance. I am also thankful to Qibo Tao and Chen Dali for his help in data analyses. Finally, I would like to thank Prof. Carol Baskin and Baskin for their advice and valuable comments on this manuscript that have helped to enrich it.

\section{Conflicts of Interest}

All the authors do not have any possible conflicts of interest.

\section{References}

[1] Wilson, T. B. and Witkowski, E. T. F. Water requirements for germination and early seedling establishment in four African savanna woody plant species. Journal of Arid Environments 1998, 38 (4), 541-550.
[2] Alamgir, M. and Hossain, M. K. Effect of pre-sowing treatments on germination and initial seedling development ofAlbizia saman in the nursery. Journal of Forestry Research 2005, 16 (3), 200-204.

[3] Eisa, M. A., Roth, M. and Sama, G. October. Acacia senegal (gum Arabic tree): Present role and need for future conservation/Sudan. In Deutscher Tropentag 2008, 1-5).

[4] Debez, A., Huchzermeyer, B., Abdelly, C. and Koyro, H. W. Current challenges and future opportunities for a sustainable utilization of halophytes. In Sabkha Ecosystems 2010, 59-77.

[5] Kassa, A., Alía, R., Tadesse, W., Valentin, P. and Bravo, F. Seed germination and viability in two African Acacia species growing under different water stress levels. African Journal of Plant Science 2010, 4 (9), 353-359.

[6] Staver, A. C., Archibald, S. and Levin, S. Tree cover in sub-Saharan Africa: rainfall and fire constrain forest and savanna as alternative stable states. Ecology 2011, 92 (5), 1063-1072.

[7] Zhao, P., Capella-Gutierrez, S., Shi, Y., Zhao, X., Chen, G., Gabaldon, T., et al. Transcriptomic analysis of a psammophyte food crop, sand rice (Agriophyllum squarrosum) and identification of candidate genes essential for sand dune adaptation. BMC Genomics 2014, 15, 872.

[8] Witcombe, J. R., Hollington, P. A., Howarth, C. J., Reader, S. And Steele, K. A. Breeding for abiotic stresses for sustainable agriculture. Philos. Trans. R. Soc. Lond. B Biol. Sci 2008, 363, 703-716.

[9] Price, A. H., Cairns, J. E., Horton, P., Jones, H. G. and Griffiths, $\mathrm{H}$. Linking drought-resistance mechanisms to drought avoidance in upland rice using a QTL approach: progress and new opportunities to integrate stomatal and mesophyll responses. Journal of Experimental Botany 2002, 53, 989-1004.

[10] Escobar, T. A., Pedroso, V. M., Bonow, R. N. and Schwengber, E. B. Overcoming dormancy and temperatures for seed germination of Acacia caven (Mol.) Mol. Revista Brasileira de Sementes, 2010, 32 (2), 124-130.

[11] Francis, J. A. and Vavrus, S. J. Evidence linking Arctic amplification to extreme weather in mid-latitudes. Geophysical Research Letters. 2012, 39 (6).

[12] Beck, H. E., Zimmermann, N. E., McVicar, T. R., Vergopolan, N., Berg, A. and Wood, E. F. Present and future Köppen-Geiger climate classification maps at $1-\mathrm{km}$ resolution. Scientific data 2018, 5: 180-214.

[13] Gremmert, S., Conner, K. J., Bateman, C. D. and Hruby, J., Honeywell International Inc. Synthetic airborne hazard display. U.S. Patent. 2004, 6: 828-922.

[14] Covell, S., Ellis, R. H., Roberts, E. H. and Summerfield, R. J. The influence of temperature on seed germination rate in grain legumes: I. A comparison of chickpea, lentil, soyabean and cowpea at constant temperatures. Journal of Experimental Botany 1986, 37 (5), 705-715.

[15] Allen, P. S., Meyer, S. E. and Khan, M. A. Hydrothermal time as a tool in comparative germination studies. Hydrothermal time as a tool in comparative germination studies 2000, 401-410. 
[16] Bradford, K. J. Applications of hydrothermal time to quantifying and modeling seed germination and dormancy. Weed Science 2002, 50 (2), 248-260.

[17] Allen, P. S., R. L. Benech-Arnold, D. Batlla, and K. J. Bradford Modeling of seed dormancy. In K. J. Bradford and $\mathrm{H}$. Nonogaki [eds.], Seed development, dormancy, and germination 2007, 72-112.

[18] Trudgill, D. L., Honek, A. D. L. I., Li, D. and Straalen, N. V. Thermal time-concepts and utility. Annals of Applied Biology 2005, 146 (1), 1-14.

[19] Hardegree, S. P. Predicting germination response to temperature. I. Cardinal-temperature models and subpopulation-specific regression. Annals of Botany 2006, 97 (6), 1115-1125.

[20] Masamba, C. Presowing seed treatments on four African Acacia species: appropriate technology for use in forestry for rural development. Forest Ecology and Management 1994, 64 (2-3), 105-109.

[21] Huang, W., Wang, Y. and Hu, X. Germination responses of three desert plants to temperature and water potential. Acta Prataculturae Sinica 2009, 18 (3), 171-177.

[22] Zeng, Y. J., Wang, Y. R. and Zhang, J. M. Is reduced seed germination due to water limitation a special survival strategy used by xerophytes in arid dunes? Journal of Arid Environments 2010, 74 (4), 508-511.

[23] Wang, M. Y., Liu, W., Liu, K. and Bu, H. Y. The base temperature and the thermal time requirement for seed germination of 10 grass species on the eastern Qinghai-Tibet Plateau. Pratacultural Science 2011, 28, 983-987.

[24] Hu, X. W., Wang, J. and Wang, Y. R. Thermal time model analysis for seed germination of four Vicia species. Chinese Journal of Plant Ecology 2012, 36, 841-848.

[25] Kazemi, K. and Eskandari, H. Does priming improve seed performance under salt and drought stress. Journal of Basic and Applied Scientific Research 2012, 2 (4), 3503-3507.

[26] Sadeghi, S., Rahnavard, A. and Ashrafi, Z. Y. Study of respond seeds wheat (Triticum aestivum L.) to osmotic priming, temperatures and local seed masses. Journal of the Botanical Research 2009, 2 (2), 69-73.

[27] Yari, L., Aghaalikani, M. and Khazaei, F. Effect of seed priming duration and temperature on seed germination behavior of bread wheat (Triticum aestivum L.). ARPN Journal of Agricultural and Biological Science 2010, 5 (1), 1-6.

[28] Kaur, S., Gupta, A. K. and Kaur, N. Seed priming increases crop yield possibly by modulating enzymes of sucrose metabolism in chickpea. Journal of Agronomy and Crop Science 2005, 191 (2), 81-87.

[29] Ghassemi-Golezani, K., Aliloo, A. A., Valizadeh, M. and Moghaddam, M. Effects of different priming techniques on seed invigoration and seedling establishment of lentil (Lens culinaris Medik). Journal of Food Agriculture and Environment 2008, 6 (2), 222.

[30] Farooq, M., Basra, S. M. A., Rehman, H. and Saleem, B. A. Seed priming enhances the performance of late sown wheat (Triticum aestivum L.) by improving chilling tolerance. Journal of Agronomy and Crop Science 2008, 194 (1), 55-60.
[31] Ellis, R. H., Covell, S., Roberts, E. H. and Summerfield, R. J. The influence of temperature on seed germination rate in grain legumes: II. Intraspecific variation in chickpea (Cicer arietinum L.) at constant temperatures. Journal of Experimental Botany 1986, 37 (10), 1503-1515.

[32] Benzing, D. H. Bromeliaceae: profile of an adaptive radiation. Cambridge University Press. 2000.

[33] Kheloufi, A. Germination of seeds from two leguminous trees (Acacia karroo and Gleditsia triacanthos) following different pre-treatments. Seed Science and Technology. 2017, 45 (1): 259-262.

[34] Yousif. M. A. I, Yan R. W, Xiao W. H. (2019). Seed dormancy and dormancy breaking of selected Acacia species from Sub-Saharan Africa. Journal of Seed Science and Technology, $47,2,1-14$.

[35] Chen, G., Zhao, J., Zhao, X., Zhao, P., Duan, R., Nevo, E. et al. A psammophyte Agriophyllum squarrosum (L.) Moq.: a potential food crop. Genet. Res. Crop Ev. 2014, 61, 669-676.

[36] Walters, M., Midgley, J. J. and Somers, M. J., 2004. Effects of fire and fire intensity on the germination and establishment of Acacia karroo, Acacia nilotica, Acacia luederitzii and Dichrostachys cinerea in the field. BMC ecology, 4 (1), p. 3.

[37] Belsky, A. J., Amundson, R. G., Duxbury, J. M., Riha, S. J., Ali, A. R. and Mwonga, S. M. The effects of trees on their physical, chemical and biological environments in a semi-arid savanna in Kenya. Journal of applied ecology. 1989, 1005-1024.

[38] Dossa, E. L., Diedhiou, S., Compton, J. E., Assigbetse, K. B. and Dick, R. P. Spatial patterns of P fractions and chemical properties in soils of two native shrub communities in Senegal. Plant and Soil. 2010, 327: 185-198.

[39] Kaufmann, M. R. and Eckard, A. N. Evaluation of water stress control with polyethylene glycols by analysis of guttation. Plant physiology 1971, 47 (4), 453-456.

[40] Cheng, Z. and Bradford, K. J. Hydrothermal time analysis of tomato seed germination responses to priming treatments. Journal of Experimental Botany 1999, 50 (330), 89-99.

[41] Finney, D. J. Probit Analysis: $3 d$ Ed. Cambridge University Press. 1971.

[42] Ellis, R. H., Simon, G. and Covell, S. The influence of temperature on seed germination rate in grain legumes: III. A comparison of five faba bean genotypes at constant temperatures using a new screening method. Journal of Experimental Botany 1987, 38 (6), 1033-1043.

[43] Ellis, R. H. and Butcher, P. D. The effects of priming and natural differences in quality amongst onion seed lots on the response of the rate of germination to temperature and the identification of the characteristics under genotypic control. Journal of Experimental Botany 1988, 39 (7), 935-950.

[44] Hu, X. W., Zhou, Z. Q., Li, T. S., Wu, Y. P. and Wang, Y. R. Environmental factors controlling seed germination and seedling recruitment of Stipa bungeana on the Loess Plateau of northwestern China. Ecological research 2013b, 28 (5), 801-809.

[45] Gummerson, R. J. The effect of constant temperatures and osmotic potentials on the germination of sugar beet. Journal of Experimental Botany 1986, 37 (6), 729-741. 
[46] Bradford, K. J. A water relations analysis of seed germination rates. Plant Physiology 1990, 94 (2), 840-849.

[47] ISTA, Association. International Rules for Seed Testing: edition. 2010.

[48] Tobe, K., Zhang, L., Qiu, G. Y., Shimizu, H. and Omasa, K. Characteristics of seed germination in five non-haplotypic Chinese desert shrub species. Journal of Arid Environments $2001,48,101$.

[49] Danthu, P., Ndongo, M., Diaou, M., Thiam, O., Sarr, A., Dedhiou, B. and Vall, A. O. M. Impact of bush fire on germination of some West African acacias. Forest Ecology and Management. 2003, 173 (3): 1-10.

[50] Fenner, M. and Thompson, K. The ecology of seeds. Cambridge University Press. 2005.

[51] Bochet, E., García-Fayos, P., Alborch, B. and Tormo, J. Soil water availability effects on seed germination account for species segregation in semiarid roadslopes. Plant and Soil 2007, 295 (1-2), 179-191.

[52] Ramírez-Tobías, H. M., Peña-Valdivia, C. B., Trejo, C. and Vaquera, H. Seed germination of Agave species as influenced by substrate water potential. Biological research 2014, 47 (1), p. 11.
[53] Gharoobi, B., Ghorbani, M. and Ghasemi, N. M. Effects of different levels of osmotic potential on germination percentage and germination rate of barley, corn and canola. 2012.

[54] Varier, A., Vari, A. K. and Dadlani, M. The subcellular basis of seed priming. Current Science 2010, 450-456.

[55] Liu, W., Liu, K., Zhang, C. H. and Du, G. Z. Effect of accumulated temperature on seed germination-A case study of 12 Compositae species on the eastern Qinghai-Tibet Plateau of China. Chinese Journal of Plant Ecology 2011, 35, 751-758.

[56] Trudgill, D. L., Squire, G. R. and Thompson, K. A thermal time basis for comparing the germination requirements of some British herbaceous plants. The New Phytologist 2000, 145 (1), 107-114.

[57] Cochrane, A., Hoyle, G. L., Yates, C. J., Wood, J. and Nicotra, A. B. Predicting the impact of increasing temperatures on seed germination among populations of Western Australian Banksia (Proteaceae). Seed Science Research 2014, 24 (3), 195-205.

[58] Wang, J. H., Baskin, C. C., Chen, W. and Du, G. Z. Variation in seed germination between populations of five sub-alpine woody species from eastern Qinghai-Tibet Plateau following dry storage at low temperatures. Ecological research 2010, 25 (1), 195-203. 